This version will appear, in an edited form, in Science in Context. Please do not quote from, or reproduce, this version without the written permission of the corresponding author, E. Roy Weintraub (erw@duke.edu).

\title{
Siting the New Economic Science: The Cowles Commission's Activity Analysis Conference of June 1949
}

Till Düppe and E. Roy Weintraub

May 2013

\begin{abstract}
In the decades following WWII, the Cowles Commission for Research in Economics came to represent new technical standards that informed most advances in economic theory. The public emergence of this community was manifest at a conference held in June 1949 titled Activity Analysis of Production and Allocation. Our history of this event situates the Cowles Commission among the institutions of post-war science in-between National Laboratories and the supreme discipline of Cold War academia, mathematics. Although the conference created the conditions under which economics, as a discipline, would transform itself, the participants themselves had little concern for the intellectual battles that had defined prewar university economics departments. The conference bore witness to a new intellectual culture in economic science based on shared scientific norms and techniques un-interrogated by conflicting notions of the meaning of either science or economics.
\end{abstract}

JEL Classification: B2, C0

Keywords: Cowles Commission, activity analysis, linear programming, general equilibrium theory, von Neumann, Koopmans, Dantzig, fixed point theorems 


\title{
Siting the New Economic Science: The Cowles Commission's Activity Analysis Conference of June $1949^{1}$
}

\author{
Till Düppe and E. Roy Weintraub
}

It may seem to be a stark paradox that, just when mathematics has been brought close to the ultimate

in abstractness, its applications have begun to multiply and proliferate in an extraordinary fashion"

(Stone 1961: 720)

\section{"The time was ripe"}

In December 1948, in one of the hotel rooms at the annual meeting of the American Economic Association, seven scholars with various backgrounds but similar interests conceived the idea of a conference: Tjalling Koopmans, Harold Kuhn, George Dantzig, Albert Tucker, Oskar Morgenstern, and Wassily Leontief (see Kuhn 2008). One of them, Tjalling Koopmans, who in summer of 1948 had become the Research Director at the Cowles Commission for Research in Economics, took the initiative. He did so in the context of a research contract with the RAND Corporation that he signed in January 1949 titled 'Theory of Resource Allocation'. The central idea of the conference was to develop the theory of linear programming, one of the successful methods of planning that had been developed in wartime research, and extend it to a more general economic theory of production. The contract called for Koopmans to bring together a small group of individuals who had been working on these kinds of projects to a conference on Activity Analysis of Production and Allocation. He scheduled it for June 20-24, 1949.

That conference defined, more than any other single event, the emergence of a new kind of economic theory growing from game theory, operations research, and linear programming and the related mathematical techniques of convex sets, separating hyperplanes, and fixed-point theory. The conference was the "coming out party" of the community that would transform the practices of academic economists for decades to come. It established the

1 University of Quebec at Montreal and Duke University. Preliminary versions of this article have been presented at various seminars and conferences by either or both of the two authors at Duke University, HumboldtUniversity in Berlin, the University of Mainz, the University of Athens, and the University of Moscow. Portions of it have been drawn from material in Chapters 4 and 5 of the authors' forthcoming book (Düppe and Weintraub 2014). With the usual caveat we thank Roger Backhouse, Bruce Caldwell, Lorraine Daston, Verena Halsmayer, Neil B. De Marchi, Mary Morgan, the journal editor, and two anonymous referees for detailed comments. 
historical conditions for economics to become a modeling science. What later would be a commonplace for economists was discussed in nuce, in an early state when the boundaries between the theories were not yet drawn, their doxic elements not yet settled, and most importantly, their disciplinary commitments not yet formed.

Many of the young scholars who participated in the conference would later recall how the conference transformed their intellectual lives and heralded a new era. 1972 Nobel Prize winner Kenneth Arrow, for example, would call the conference a "key step in unifying and diffusing the developments in linear programming and relating them to the theory of general equilibrium" - the theory that would shape economic modeling for several generations of economists to come. He continued:

This has been regarded by all those in the field, not only those in the Cowles group, as a decisive event. The exchange of ideas was crucial... The papers at the conference called scholars' attention to each other; they clarified the concepts and laid a firm foundation for future work. The first proof of the validity of the simplex method was among its most important products. For the development of general equilibrium theory, the most important paper was Koopmans' in which he developed the theory of production from linear activity analysis... This synthesized all the previous lines of study. (Arrow 1991: 12-13)

For Arrow, activity analysis framed the theory of production as it would later enter into general equilibrium analysis. In the aftermath of the conference he, simultaneously with Gerard Debreu and Lionel McKenzie, begin working on an existence proof in general equilibrium theory that would be the "door that opens into the house of analysis" (Mas-Colell 1995: 584). Indeed, nearly all of the ingredients of the future existence proof in general equilibrium theory were on the conference table, though it was too soon to put the separate pieces together. On the very first page of the conference volume's introduction Koopmans mentioned the early work on existence of equilibrium in Vienna by Karl Schlesinger and Abraham Wald in Menger's Mathematical Colloquium (Weintraub 1983), and then referred to John von Neumann's seminal paper on dynamic equilibrium (1936). Koopmans noted that "even among mathematical economists their value seems to have been insufficiently realized." (2) Harvard's Robert Dorfman would later recall that :

He [Koopmans] was excited by the implications of linear programming for the whole theory of resource allocation, which is the fundamental problem of economics. He perceived clearly that an entire economy could be thought of as solving a vast linear programming problem in which the prices that 
emerged from competitive markets played the same role as the dual variables in Dantzig's theory of linear programming. This implied that the theory of linear programming could serve as a basis for rigorous formulation of the theory of general economic equilibrium (1984: 294).

While the conference did not address the integrative character of a general equilibrium model, it nevertheless created the conditions by which this integration would take place. Specifically the extended Cowles community recognized their shared belief in the importance of mathematical rigor (creating distance from Hicks' Value and Capital (1939)), and their need to de-politicize economic theory (creating distance from Lange's market socialism). What was crucial for the transfer of ideas occurring at the conference was a commitment to method and this weakened the commitments to beliefs that are formative for disciplines. As Chandler has argued: "One might even say that the stronger the emphasis on method as such, the further we are from doxa, from belief or opinion." (2009: 733).

Indeed, the very same conference would later be called the $0^{\text {th }}$ conference of a field (and society) unrelated to economics: mathematical programming. George Dantzig, who himself presented four papers, recalled:

In $1949 \ldots$ the first conference on mathematical programming (sometimes referred to as the first Symposium on Mathematical Programming) was held at the University of Chicago. Koopmans, the organizer, later titled the proceedings of the conference "Activity Analysis of Production and Allocation". Economists like Koopmans, Arrow, Samuelson, Hurwicz, Dorfman, Georgescu-Roegen, and Simon; mathematicians like Tucker, Kuhn, and Gale; and Air Force types like Marshall Wood, Murray Geisler, and myself all made contributions. The time was ripe... The Proceedings of the Conference remains to this very day an important basic reference, a classic! (Dantzig 1982: 46)

The conference was the origin of what would within a decade provide closure to the discipline of economics. At the same time it created a field in applied mathematics in which hardly any economist would become active. When Koopmans received the Nobel Prize in 1975 he hesitated in accepting it as he thought that Dantzig and he should share it equally. Dantzig took linear programming into non-economics disciplinary waters using it to construct a new theory in organizational and management science that would come to be taught in engineering and business departments about to separate themselves from economics departments during those postwar years.

Those who came to the economics profession after the conference joined a community that had been freed from prewar debates about the right way to 
"do" economic analysis. They could simply assume, as their predecessors could not, the values of rigor shared at the conference. Gerard Debreu, who came to the US in the fall of 1949, recalled the shared enthusiasm for convexity analysis (in contrast to differential calculus, the mathematics previously used by economists) that the conference had introduced and that he would soon employ when using mathematical proof techniques in general equilibrium analysis.

[W]ith the passage of time, that conference has stood out more and more clearly as an important moment in the history of mathematical economics. The theory of production was looked at from new viewpoints; the computation of optimal production programs received emphasis; convex analysis was developed for the needs of production theorists and extensively applied; the observance of mathematical rigor was taken for granted; and another demonstration of the fecundity of interaction among the economists, mathematicians, and operations researchers was given. (Debreu 1983: 30, emphasis added)

Cowles liberated many mathematicians interested in the social sciences from the awkward feeling that they had to justify the use of mathematics in economics - instead, its importance could be taken for granted. "At Cowles I came to think, very quickly, that full understanding of a problem required no compromise whatsoever with rigor" (Debreu, quoted in Weintraub 2002: 153).

As important as the conference appears in retrospect, it was not intended or planned as a path-breaking event, nor could any of the participants recognized at the time the effects it would have. Koopmans began planning the event only some months beforehand, and had sent out the invitation letters only one month before the conference while circulating drafts of papers only weeks before the meeting. The conference, as we will show, was meant to be a gathering of scholars pulling at the same string rather than the rally of a community proclaiming a new future of economic research. The Cowles Commission stood at the crossroads of various disciplines, as well as between university and national laboratories. Newly available archival material allows us to reconstruct what made this event so important.

Such an exercise is critical for understanding the "agency" of scientific change and disciplinary formation. Previous generations of historians have spoken of the change we consider as a "formalist revolution", a phrase that suggests a shared intention of a small number of scholars who managed to impose their values on the profession (e.g. Blaug 2003). Such was not the case. In fact, we show that the conference was unconcerned with the specific shape of the discipline of economics. Equally, one cannot provide a satisfactory explanation of this change by embedding it in a metanarrative concerning the postwar institutional structures of science (Mirowski 2001). Narratives focused on the role of the military in post-war economics are too often thin and unconvincing, seeing the "military-industrial complex" everywhere. 
Our story begins with a "snapshot" of the conference. We will then locate it with respect both to the history of Cowles and the landscape of U.S. science and the RAND Corporation. Finally, after connecting the conference and its participants to the mathematics departments at Chicago and Princeton, we will revisit what has up to now been the canonical account of what transformed economics in the postwar years.

\section{Snapshot}

In the wake of WWII institutions, perhaps more than individuals, mattered in science. In his conference invitation letter Koopmans identified several "groups" of participants. The "Princeton University" group was represented by the mathematicians Albert Tucker, Harold Kuhn and David Gale (who shortly before had left Princeton's mathematics department for Brown's), and the economists such as Oskar Morgenstern and Ansley Coale. The "Cowles group" included Kenneth Arrow, Murray Gerstenhaber (a mathematics department PhD student of A. A. Albert), Cliff Hildreth, Tjalling Koopmans, Stanley Reiter, and Herbert Simon. Nicholas Georgescu-Roegen came from Leontief's "Harvard Economic Project". Marshall Wood, Charles Hitch, Merrill Flood, Norman Kaplan, Paul Samuelson, Murray Geisler, George Brown, and a key figure of the conference, George Dantzig, were associated with RAND and the Air Force. In total, there were thirty-four papers and about fifty participants. Koopmans also invited John von Neumann, but he did not come. ${ }^{2}$

This list constructs the world of mathematical social science in the United States in 1949. What stands out is the interrelatedness of the groups from both governmental and academic institutions. Marshall Wood, the named representative of the Air Force, moved back and forth to RAND which was doing contract work on game theory. Samuelson, the 1947 Clark Medal winner, was visiting RAND that spring from MIT. ${ }^{3}$ Data issues confronted the Bureau of

2 Other invitees with different affiliations include Robert Dorfman, Harlan Smith, and Yale Brozen. Among those who attended the conference but did not present papers were Armen Alchian, Evsey Domar, and others from the Cowles Commission like Jean Bronfenbrenner Crockett, George Borts, Carl Klahr, Jacob Marschak, and William Simpson. From Princeton Thomson Whiten and Max Woodbury were in attendance, while individuals like Tibor de Scitovsky and Oswald Brownlee were present as well. Individuals who presented papers that were not incorporated in the volume included Merrill Flood, David Hawkins, Leonid Hurwicz, Abba Lerner, and Marvin Hoffenberg. Among those invited but not in attendance, besides von Neumann, wasWassily Leontief.

${ }^{3}$ At RAND, Samuelson was working at Hitch's request on a monograph that would explain how linear programming might be improved by economic theory, which years later would evolve into Samuelson, Dorfman and Solow (1958). Samuelson's role in the conference is fully described in Backhouse (2012). However Cowles was not the group Samuelson was connected with. He was asked to contribute to the conference in order to link linear programming 
Labor Statistics, the Council of Economic Advisers, and Leontief's Harvard Economic Project as well as Cowles, where Lawrence Klein had from 1944 to1947 been constructing a national econometric forecasting model along lines that Jan Tinbergen had pioneered. Evsey Domar at Johns Hopkins and Tibor Scitovsky at Stanford were studying technological change. The mathematician Mina Rees, representing the Navy, had been supporting work in mathematical economics through her position in the Office of Naval Research: Morgenstern at Princeton as well as Arrow at Stanford had been receiving ONR funds as had John von Neumann as a consultant at RAND. In 1949 the ONR would fund the Logistic Branch of the Mathematical Sciences Division led by Fred Rigby: both Arrow and Koopmans collaborated there (Dalmedico 1996: 183). It was a very small world, a world that was both separate from the older generation of the Econometric Society and to a notable extent from the visible sites of academia, the economics departments of the Ivy League universities.

The theories discussed at the conference likewise stood "between" the concerns of academia and the national laboratories. As Koopmans described the purpose of the meeting to his invitees (May 11, 1949, PAS, "Koopmans"):

[The conference concerns] a related group of techniques for the analysis and planning of resources allocation, that have become known under the name 'linear programming'. The problem area involved includes: the inter-industry relations technique developed by W. Leontief, and the related data and aggregation problems; the programming models developed by G. B. Dantzig and Marshall K. Wood of the Air Force Department to facilitate the handling of complicated allocation problems under administrative control; the discussions of $\mathrm{J}$. Meade, O. Lange, A. P. Lerner, and others, in the economic literature, of the function of a price system in furthering efficient allocation of resources where decisions are made in many independent units; the discussion of models of technological change by $\mathrm{H}$. A. Simon and others, etc. The unifying element in these diverse problems is the use of models assuming that fixed ratios of inputs and outputs characterize each productive activity - an assumption less restrictive than it seems at first.

with economic theory, which is to say that for other participants this link was all but obvious. Samuelson, with his J.B. Clark medal in 1947, had different responsibilities in the economics profession compared to the individuals we treat in this paper: they were marginalized in the larger economics community in the late 1940s, he was not. 
The theories central to the conference were thus Leontief's input-output model as restated by Samuelson, linear programming and its applications as shaped by Dantzig's simplex algorithm, and traditional welfare economics as developed by Bergson, Lange and Lerner in the 1930s. ${ }^{4}$ Looking back from today, only a small number of the particular models would end up in economics textbooks. Though activity analysis was an important ingredient for reconstructing production theory in such way that it was amenable to an axiomatization, it did itself not survive this integration into a general equilibrium framework. ${ }^{5}$ Similarly Leontief's input-output models were designed to examine inter-industry relationships, but the fixed nature of the production technology contrasted with traditional models in which inputs could be substitutes for one another as their relative prices changed. Leontief's model, in the years to come, would not contribute to the integration of economic theory as general equilibrium theory would do, even though, for example, Georgescu-Roegen thought of input-output analysis as "the first attempt to apply the general equilibrium theory to the analysis of an economic reality" (Koopmans 1951: 98).

Neither would Dantzig's simplex algorithm enter economics textbooks as it entered other textbooks. ${ }^{6}$ Two years later, in 1951, Dantzig would organize what then would be called the $1^{\text {st }}$ of the conferences on mathematical programming, the activity analysis conference being the $0^{\text {th }}$, jointly with Alex Orden and Leon Goldstein titled "Linear Inequalities and Programming" at the National Bureau for Standards. No one who would become relevant to Cowles or economics was present. The Mathematical Programming Society would not be related to the discipline of economics at all, but would instead come to be tagged as "mathematics and its applications in industry, business, and technology". 7

${ }^{4}$ The list of memoranda that had been circulated prior to the conference accordingly included four papers by Dantzig, Samuelson's and Harlan and Smith's comments on Leontief, several papers by Koopmans on activity analysis, and also the English translation of Schlesinger's paper and Wald's "Über die Produktionsgleichungen der ökonomischen Wertlehre" (1935). Other memoranda included Gale on "Convex Cones", and Gale, Kuhn and Tucker, and Brown on computation.

5 Activity Analysis did not take account of independent production decisions and is thus linked to optimization theory rather than equilibrium analysis (see Arrow 2008: 165).

${ }^{6}$ Though Dantzig's algorithm would be cited in textbooks for some time, it would slowly be replaced by other methods. To be sure, for many economists, particularly those who considered economic theory to be a theory of optimal choice rather than a theory of the social structure, linear programming would always represent a "bottom up" approach to optimization. See, for example, Arrow 2008: 161.

7 Its founding members were hardly known among economists. Individuals like A. Orden, J. Abadie, M.L Balinski, P. Wolfe, and G. Zoutendijk were employed by mathematics departments (see Cottle 2010). At the same time several other associations in applied mathematics were formed: 
The conference thus opened the gate allowing traffic in two directions: mathematical rigor flowed into economic theory, and economic theory flowed into mathematics reinforcing its applications. This was made possible by the fact that among the participants there was no clear commitment to the discipline of economics, even as they agreed on a general notion of the economic relevance of their research. What united the conferees was their enthusiasm about the new techniques that had been developed in various institutions within and without academia in unstable political contexts. Understanding this transdisciplinary format of the conference requires understanding the institutional milieu within which the Cowles Commission operated in this immediate post-war period.

\section{The Cowles Commission between academia and laboratory}

The Cowles Commission for Research and Economics had been founded in 1932 in Colorado, two years after the foundation of the Econometric Society. It was named after its founder Alfred Cowles, a wealthy investment adviser, who hoped for better predictions of stock market behavior by using mathematical and statistical tools. For this purpose he hired well-known economists such as Irving Fisher, Harold Hotelling, and Ragnar Frisch to work part time, or as consultants, to the Commission. Even though the research produced did not help his business affairs, he continued on as the patron of many of the members of the young Econometric Society. In 1939, in order to avoid state taxes in Colorado, the Cowles Commission searched for a new home and found it at the University of Chicago.

This move was fortuitous. Chicago had been important in statistical economics, and Henry Schultz, one of the founding members of the Econometric Society, had attempted to unite theory and statistics in his work on estimating demand curves. Chicago's willingness to host Cowles was in part related to the fact that Schultz had recently died in an automobile accident. From the Department of Economics, only Oskar Lange was part of the Cowles group. Theodore Yntema, a former student of Schultz's, became Research Director in 1939. As he became more involved in war related work over the next few years, some of his duties seem to have been handled by Lange: he for example wrote to Samuelson and others in 1940-41 asking about possible recruits for Cowles. Instead of seeking local faculty to hire, the Cowles Commission recruited from the pre-WWII European émigré community. As Roy Epstein wrote in his engaging history of econometrics: "It is also appropriate to record Cowles's sponsorship of refugees from Nazism, in particular Abraham

Wald and Horst Mendershausen. Perhaps owing to the liberal and internationalist outlook of the Cowles family, the Commission soon became a

Association for Computing Machineries (1947), Industrial Mathematical Society (1949), Operations Research Society of America (1952), Society for Industrial and Applied Mathematics (1952) (see Dalmedico 1996). 
notable stopover point for many foreign economists visiting the United States. ${ }^{8 "}$ (Epstein 1987: 60-61) From Marschak's arrival from Oxford via the New School for Social Research as Research Director in 1943, the Commission became increasingly attractive to technically trained European scholars most of them well-known to Marschak. ${ }^{9}$ Marschak had grown up in the Ukraine, was educated in Germany, and had headed the Oxford Statistics Institute. Herbert Scarf recalled:

Marschak was a scholar of great intellectual force, curiosity, and initiative. As director [of Cowles] he continued the program of summer conferences, but now there was a dramatic increase in the number of visitors and the size of the resident staff.... Leonid Hurwicz had been recruited by Yntema [Cowles Research Director from 1941-43], and in the next several years Trygve Haavelmo, Koopmans, Herman Rubin, Lawrence Klein, Theodore Anderson, Kenneth J Arrow, Herman Chernoff, Herbert Simon, and other distinguished statisticians and economists were to be associated with the Commission in one way or another. (Scarf 1995: 277)

The Cowles Commission was uniquely located at the crossroads of forces that shaped post-war academia. The end of the WWII reconfigured the institutions of US science as it boosted optimism that the scientific achievements that had enabled victory could similarly enable a prosperous peacetime society. ${ }^{10}$ The war-ending shock of the August 1945 atomic bombs,

${ }^{8}$ It cannot be emphasized strongly enough that the 1930s were a time of both overt and covert anti-Semitism in American higher education. The attempts by some academics, and foundations like Rockefeller, to sponsor and place European mostly Jewish refugee scholars is a well-told story (see e.g. Feuer 1982; Hollinger 1996; Lipset 1971; Lyman 1994; Scherer 2000, etc.).

${ }^{9}$ Cowles' turn towards theory and its concomitant collectivist culture was certainly prefigured under Marschak, specifically in the form of a top-down approach to econometrics. It was also Marschak, who, as a real novelty in the organization of research groups, launched bi-weekly research seminars running concurrently with the summer conferences at Cowles. One might argue that the Activity Analysis Conference reinforced what began with Marschak by adding a non-econometric Walrasian dimension in a context of programming (see Epstein 1987).

${ }^{10}$ As is well known, American economists had contributed to the centrally planned war economy. In addition to the economists' usual jobs at the Treasury, Agriculture, Commerce, or the Office of Price Administration, economists worked on military applications in the operations research community, and the nascent game theory community in order to solve the kinds of search problems 
and the resulting Japanese surrender, supported the belief that planned government support of science would sustain western freedoms (Hollinger 1996, 160-64). It also resulted in a re-evaluation of the meaning of the pure and the applied - they appeared to have more in common than expected (Dalmedico 2001).

The pressing question became how to organize science in the post-war period (see e.g. Dalmedico 1996, Leggon 2001, 221-224). In 1944-45 the U.S. Congress commissioned a study of how scientific research should be funded. There appeared to be two possible models. The first was to have Congress set up a research agency and then fund or earmark projects prioritized by national needs, as had been done during the war. Alternatively Congress could give money to the scientists directly or through their employers, letting peer review and competition solve the allocation problem politically unencumbered by pork barrel politics. The former model meant continuity with the wartime regime; the latter meant a return to the ideal vision of the autonomy of science. The negotiations between these two models required balancing maintenance of some elements of wartime scientific institutions and practices while simultaneously rejecting those elements that did not fit well with a democratic peacetime society.

And so universities were drawn into two not necessarily compatible roles: on the one hand, they were to host the "scientific community" which was supposed to exemplify the values of a free democratic society. The pursuit of truth among scientific peers was a model of the behavior that one would expect from a well-functioning democracy. ${ }^{11}$ On the other hand however, with the lifting of wartime secrecy, Americans learned that the success of scientists, and the technology they had brought to the war effort, had created a large government "owned" scientific community which had worked with a sense of national purpose: Oak Ridge, Hanford, and Los Alamos were the outward manifestations of this new scientific world. These institutions hosted science in ways quite apart from the democratic ideals of open universities - classified work remained taboo in universities. The continued success of science in the creation of the post-war society would thus depend upon a successful resolution of the tension

(e.g. anti-submarine warfare), allocation problems (e.g. steel for production of tanks versus battleships), computational problems (e.g. code breaking), bombing problems (e.g. low altitude high risk-high gain, versus high altitude low risk-low gain), estimation problems (e.g. of casualties) (see Dalmedico 1998: 656-658; Mirowski 2002, chapter 4; Guglielmo 2008; Leonard 2010, chapter 12; Klein to appear).

${ }^{11}$... as was propagated for example by the report of Harvard's committee on higher education General Education in a Free Society (Buck et al. 1945), or Harvard President James B. Conant's On Understanding Science (1947). These writings, as Hollinger reported, "selected from the available inventory those images of science (...) serving to connect the adjective scientific with public rather than private knowledge, with open rather than closed discourses, with universal rather than local standards of warrant, with democratic rather than aristocratic models of authority" (1996: 444). 
between continuity and reform, between transparency and secrecy, between scientific control of society and traditional values like liberty, between the autonomy of open science and its emergent social role as preserver of democracy against its enemies - a real conflict of the norms of science, as Robert Merton had said (1973: 276), representing a full-blown Kulturkampf, as Hollinger had added (1996: 155ff).

In the end, Vannever Bush's report Science: The Endless Frontier (1945), presented Congress with a mixed model for support of postwar science $^{12}$. He linked the fortunes of science to those of the government: 'Since health, well-being, and security are proper concerns of government, scientific progress is, and must be, of vital interest to the government' (Chapter 2, Section 2). By famously putting emphasis on the equal value of both "basic" and "applied" research (the former paying off in an unknown future, the latter in a near future), he muddled through the image conflict of older and newer forms of knowledge. Bush had been the Director of the Office of Science, Research, and Development (OSRD) which was to be closed in December 1947. In its place Congress would fund a National Science Foundation (to be founded in 1950) with an annual budget appropriation, and the NSF would make grants to scientists through a peer review process organized by disciplinary scientific panels. At the same time government could not give up the military infrastructure it had built up during the war. National security appeared to require that the government continue its direct funding of specific research projects on, for instance, nuclear and thermonuclear weaponry. Congress thus sponsored national laboratories that engaged in largely secret defense related work. Additionally Congress created administrative entities in support of national defense objectives. It authorized funding for the Office of Naval Research $(\mathrm{ONR})^{13}$, the Atomic Energy Commission, the National Advisory Committee for Aeronautics (later NASA), the Defense Applied Research Projects Agency (DARPA) and the Air Force's Research and Development center in Santa Monica, an initially private corporation to be known by its acronym, RAND. These research laboratories enjoyed freedoms unknown in academic institutions that had to represent epistemic virtues in public.

During Marschak's time as director, but particularly after Koopmans's research directorship beginning the summer of 1948, the Cowles Commission would find a new place in-between these two sites of the post-1945 production of knowledge. This new position of Cowles became apparent following Koopmans' newly established relationship with RAND responding to the withdrawal of one of its major funding sources, the Social Science Research

12 Historians of economics, and historians of science more generally, have only recently learned that Paul Samuelson was one of the three actual authors of the report. See Samuelson's oral history interview at http://mit150.mit.edu/infinite-history

${ }^{13}$ See Sapolsky 1990. The ONR funded most of the research in both pure and applied mathematics until the foundation of the NSF in 1950 (Dalmedico 1996). 
Council and, the Rockefeller Foundation. ${ }^{14}$ And so the Cowles Commission became a hybrid institution somewhere between these two sites of science, between a university department and a national laboratory. The activity analysis conference can be understood historically as the successful attempt to negotiate the tension that existed between these two sites, between newer and older images of knowledge. In fact this negotiation required distance from both, from military purposes on the one hand, and the economics departments on the other.

\section{Distancing from RAND}

RAND stands for the continuity of pre- and postwar research. It was founded "to insure the continuance of teamwork among the military, other government agencies, industry, and the universities." Closed off from the public, and without commitments to a disciplinary order, RAND sponsored highly eclectic research ranging across weapons systems engineering, abstract mathematical inquiry, studies in logic, computational technology, operations research, and game theory all under the label of "systems analysis". RAND was a socially committed trans-disciplinary environment without immediate relation to any of the traditional concerns of economic theory. If one can speak of a shared vision at all, it was to seek to apply the principles of rational agency to politics and warfare.

Some historians have emphasized the role of RAND for the development of Cowles' research program (see Mirowski (2002), Leonard (2010)). Mirowski goes as far as arguing that "RAND was the primary intellectual influence upon the Cowles Commission in the 1950s, which is tantamount to saying RAND was the inspiration for much of the advanced mathematical formalization of the neoclassical orthodoxy in the immediate postwar period." (2002: 208) It is vital however to recognize, as Mirowski does not, that the RAND community had no disciplinary commitments. If RAND had really been the dominant force behind Cowles' impact on economics it would not have produced a transformation of economic theory, but rather a diffusion of tools and methods of wartime research into an amalgam of research areas and proto-disciplines that were amenable to technical formulation. RAND did not provide closure to disciplines, but embedded them in a trans-disciplinary meta-science (as individuals like Anatol Rapoport and Herbert Simon had hoped for economics). For RAND, the shape of economics as a discipline was simply irrelevant. Indeed, Mirowski repeatedly points out that the commitment to economic theory, specifically traditional equilibrium analysis, served, in his terms, to "ward off cyborgs" for decades (see e.g. his 2002: 220, 255, 270). If Cowles indeed held off the cyborg's debut in economics, it must have been the case that the arcane spirit of mathematical Walrasian economic theory was the villain (or hero). The

${ }^{14}$ See Mirowski 2001: 262. Koopmans had been able to establish a relationship with RAND thanks to his time at Princeton, where he had worked closely with mathematical statisticians Samuel Wilks and Frederick Mosteller. 
inspiration for the integration of economics through the agency of equilibrium analysis thus did not come from the military ${ }^{15}$.

While RAND was not limited by disciplinary concerns, academia was. In the years to come universities, with institutions like departmental instructional units and undergraduate curricula, fostered the differentiation of scientific fields. The end of the Second World War was the beginning of a re-negotiation of the disciplinary arrangements of the late $19^{\text {th }}$ century. The rhetoric of difference between science and engineering, between pure and applied, between literary and scientific work took hold. C. P. Snow's Two Cultures emerged in this period (Ortolano 2009). As a result, mathematics departments gained an autonomy they never had before as they became independent from the physical sciences, as we discuss in the next section. At that time the "social sciences" also grew apart as differentiated disciplines of business economics (Augier and March 2011), sociology, cultural anthropology, political science, and economics (Backhouse and Fontaine 2010). This is one of the oddities of early Cold War Science: alongside the differentiation of disciplines, ongoing today, there was a shared commitment to certain kinds of techniques among the elites of these disciplines. As methods easily cross disciplinary boundaries when being detached from a system of belief in their early stages, they can later come to define these boundaries when "thickened" with doxic content (Chandler 2009).

In other words, RAND might have provided resources, but it was of no help to Cowlesmen in confronting the issue of legitimacy they faced within academia. This pressing issue is apparent in Koopmans's "Introduction" to the conference proceedings when he referred to the nature of military funding:

If the apparent prominence of military application at this stage is more than a historical accident, the reasons are sociological rather than logical. It does seem that governmental agencies, for whatever reason, have so far provided a better environment and more sympathetic support for the systematic study, abstract and applied, of principles and methods of allocation of resources than private industry. (Koopmans 1951: 4)

Apart from this rhetorical strategy of distancing from RAND, one should also note that there were a number of scholars at Cowles who had no connection with RAND or its activities. Roy Radner, Stanley Reiter, Leo Hurwicz and Gerard Debreu engaged in mathematical modeling that was more Platonist and less computational. Between Cowles and RAND stood, as we are going to see, the purity of Bourbaki mathematics. Those attracted to purity and rigor

15 Mirowski says that after 1947 "Cowles [had to] attend to its political priorities". He insinuates (Mirowski 2012: 149) that 1) RAND was a cold war (anti-communist) institution; 2) Cowles was connected by contracts and ideas to RAND in the late 1940s and 1950s; and thus 3) Cowles was corrupted by the military-industrial complex. To suggest that the group of left-thinking Cowlesmen (e.g. Marschak, Koopmans) and politically disconnected mathematicians (e.g. Debreu) were cold warriors supporting capitalist institutions by writing papers on market equilibrium is hard to fathom - perhaps they had false consciousness? 
remained rather ignorant about what their colleagues did at RAND. As Debreu for example asserted later, somewhat ambiguously:

Some of the mathematical economists I knew spent a significant part of the summer at RAND. I did not do that and that may be due to some extent, but not entirely, because I was not a U.S. citizen, and RAND was doing a number of things for the army. (...) I do not know who from Cowles went to RAND in the summer. (in Weintraub 2002: 143-145)

Some went, Debreu knew. But he preferred not to ask who went. Who knows what they do there?

\section{Distancing from Politics}

Legitimacy shaped the conflict between Cowles and its host, the University of Chicago Economics Department. One of Schultz's and later Hotelling's PhD students, Milton Friedman, was outspoken in his distaste for the theoretical approach to data-mining - a distaste that culminated in his confusing methodological essay of 1954. This conflict might have appeared to be technical in nature, but it was nourished by a climate of political suspicion. Chicago had grown into a "school" known, among American economists, as staunchly opposed to the Roosevelt administration and New Deal policies (van Horn et al. 2011). Paul Douglas had been a liberal outsider among conservative economists like Henry Simons, Jacob Viner, and Frank Knight, and their students Gregg Lewis and George Stigler. The Cowles people in contrast were a collection of European socialists and social democrats, and homegrown leftliberals. "[W]e members of the Cowles Commission," Lawrence Klein witnessed, "were seeking an objective that would permit state intervention and guidance for economic policy, and this approach was eschewed by both the National Bureau and the Chicago School" (quoted in Mirowski 2002: 243). Indeed Klein joined the Communist Part while at Cowles. Koopmans' very left-wing views at the time, not so uncommon among American scholars, found a sympathetic audience among the European social democrats at Cowles. Indeed Marschak, in his Menshevik days, had been the minister of labor in the Soviet Republic of Terek in 1918.

It was not only the economics department that questioned the legitimacy of Cowles, but the university's administrators and government officialdom at large. In that postwar period in which interest in socialism was tantamount to sedition, past Communist Party membership was grounds for employment termination, and interests in economic planning were best left unremarked, the need for de-politicization was evident to Koopmans. Even if for example Domar and Kaplan spoke at the conference on applying linear models to the Soviet economy, Koopmans would not include them in the proceedings (see Backhouse 2012). 
The fact that economists interested in advancing technical tools in economic theory, specifically Europeans, were rather "left" should not have surprised anyone at Chicago. Having fled Nazi and fascist Europe, many Cowlesmen had been active earlier in what was known as the "socialist calculation debate". Oskar Lange, who was on a leave of absence in New York from 1943-1945, resigned his professorship at Chicago in 1945 in order to help plan and build the post-war economy in Poland. It had been Lange who brought forward the Walrasian model as a planning device. ${ }^{16}$ Arrow recalled:

On returning from military service, I planned to write a dissertation which would redo Value and Capital properly, a very foolish idea. I had two motivations. One was to supply a theoretical model as a basis for econometric estimation. The other was a strong interest in planning. I would have described myself as a socialist, although one that had a strong belief in the usefulness of markets. Market socialism was a widespread view. Hotelling held it. It had been popularized especially by the works of $O$. Lange (reprinted in Lipincott 1938) and A.P. Lerner (1946). In the immediate postwar period, the idea of national planning to supplement markets was common in Western Europe, and allocation in effect was treated, in principle, as the solution of a general equilibrium system (although with many simplifications). (Arrow 2009: 7)

Since activity analysis was concerned with organizational questions of production based on systems of equations and programming, it had a clear connection with market socialism. Thus, underneath the surface interest in activity analysis was an older set of arguments about the possibility that some kind of socialist planning model could produce the same efficient outcomes that a competitive market economy might produce. Discussing a theory of production in the second half of the 1940s in Chicago unavoidably evoked Lange's theory of planning.

It was this historical burden of competitive analysis that increased concerns about the legitimacy of the Cowles research program. Koopmans' could not avoid mentioning Ludwig von Mises and Lange on the first pages of

${ }^{16}$ The original statement of the central problem went back at least to Barone, who pointed out that the equilibrium prices were "solved" by the market supply and demand equations: if there were as many equations as unknowns, a solution was assured, and that equilibrium solution was descriptive for any economy, market driven or socialist. Thus the market process could in principle be "found" either through market activity, or by the calculation of a planner who had access to the supply and demand relationships. In principle, a centrally planned economy could replicate the allocative efficiency of a market economy. 
the Proceedings' introduction in the following terms: "Particular use is made of those discussions in welfare economics (opened by a challenge of L. von Mises) that dealt with the possibility of economics calculation in a socialist society. The notion of prices as constituting the information that should circulate between centers of decision to make consistent allocation possible emerged from the discussion by Lange, Lerner and others" (1951: 3). When Koopmans circulated the introduction prior to its publication to various participants, it was Paul Samuelson who suggested that he simply skip reference to Lange and von Mises altogether (Koopmans, PAS Papers). But for Koopmans, who as the spokesman of the conference sought a conceptual framework that would mediate conflicting demands, this question had to be settled rather than silenced. For him, planning was no longer a political option but an organizational necessity.

The underlying idea of the models of allocation constructed is that the comparison of the benefits from alternative uses from each good, where not secured by competitive market situations, can be built into the administrative processes that decide the allocation of that good. This suggestion is relevant, not only to the problems of a socialist economy, but also to the allocation problems of the many sectors of capitalist or mixed economies where competitive markets do not penetrate. (Koopmans 1951: 3) $^{17}$

Economies "where competitive markets do not penetrate" in 1949 immediately evoked the war economy which necessarily had been a centrally planned economy. The U.S. did not achieve victory in the war by letting free or competitive markets decide what armaments to produce and how scientists should be allocated to particular military tasks. Koopmans clearly walked a tightrope in a politically heated world. He urged the use of a theory of planning in ways compatible with a democratic U.S. society. Koopmans attempt to de-

17 Koopmans, in a speech in December 1949 at a joint session of the AEA, the American Statistical Society, and the Econometric Society, reviewed the earlier calculation debate and then stressed the non-ideological character of planning by referring to the work of Dantzig and Wood in the context of military planning: "The earlier discussions had been concerned too much with absolute institutional categories encompassing the entire economy. Even in the capitalistic enterprise economy there are many sectors where the guide-posts of a competitive market are lacking and explicit analysis of the allocation problem is needed. Another example may be added to that discussed by Wood and Dantzig. In determining the best pattern of routing of empty railroad cars there are no market quotations placing differential prices on alternative geographic locations of cars. Present arrangements permit this complicated problem to be handled only by administrative direction" (1951b: 457). 
politicize the theory of production and welfare economics through activity analysis was an attempt to deal with the tension under which the Cowles Commission was working: utilizing the planning tools developed during war time research and reshaping their previous meanings to the new environment. We have evidence of this tightrope-walk as he tried to frame a central notion of activity analysis: prices! On March 1, 1950, Koopmans wrote to Samuelson:

I have been thinking further about the best terminology for what has been variously called shadow prices, accounting prices, efficiency prices. Of these, I now like efficiency prices best, because it indicates that efficiency is presupposed before the price concept can be constructed. However, the word price still has too much of a market connotation to satisfy me completely. How about the good old word "value"? This, of course, has been abused in various metaphysical sense, and has therefore been avoided for some time by the more careful economists. However, I wonder if it could not by now be re-introduced in what is by now a very proper sense. ${ }^{18}$

Koopmans' insecurity as late as 1950 about such a basic question as whether to speak of "prices" or of "values" can only be understood against the background of the political poison that "planning" had become in the McCarthy period.

This confusion regarding terminology would later be at the heart of a debate about scientific priority: Leonid Kantorovich independently had discovered the principles of linear programming in the Soviet Union (see Bockman and Bernstein 2008). Whatever might have been the reason for giving Kantorovich and Koopmans the Nobel Prize jointly, it produced a debate that echoed the terms of the calculation debate. Kantorovich, of course, did not use the term "prices", which became a problem once his article was to be translated. Without using this term, could his formulation of linear programming be considered the same discovery? If a theory of socialist planning and a market theory are formally equivalent, this difference of framing would not translate to a difference of credit. Yet Abraham Charnes and W.W. Cooper argued against the equivalent achievement of Kantorovich on the basis of an essentialist notion of prices, assuming that a Stalinist state could not bring forth work worthy a Nobel Prize. Of course formal equivalence versus irreducibility of an economic theory of socialism and markets had been the core of the calculation debate between Lange and von Mises.

${ }^{18}$ See also his AEA speech saying that the "price concept ... is independent of the notion of a market. The foundations on which this price concept is erected consist only of the technological data (input-output coefficients of all activities) and the requirement of efficiency)... The price concept is found to be a mathematical consequence of an efficient choice of activity levels." (Koopmans 1951b: 461-2) 
In sum, the spirit of the conference, responding to pressures of legitimacy, was supposed to be a-political. Applying new tools to economic theory, Koopmans' research program stands for a de-politicization of a kind of economic theory previously used in contexts of socialist or war planning. The tacit agreement among the participants was that the significance of technical tools derived in some way or the other from the possibility of social engineering - whatever might be the political or moral justification for doing so. This depoliticization of the theory, as we see in the next section, was not so much achieved by Koopmans's rhetorical moves and re-interpretations. Instead it was an unintended consequence of the theory's "moving" to the mathematics department.

\section{Mathematics at Chicago and Princeton}

The self-protective a-political turn was apparent not just to the economists at the Cowles Commission but equally to mathematicians who had been active in scientific war engineering, especially at Princeton and Chicago (where most mathematicians present at the conference were located). Both departments had been involved in the recruitment of mathematicians during WWII, and both were to become central to the post-war institutions of science. Without understanding the influence of Princeton and Chicago mathematicians on Cowlesmen, we cannot understand the transformation of economic theory that was birthed there.

After WWII, mathematics needed to balance newly emerging fields of application that threatened its traditional internal organization (partial differential equations, probability, and statistics). Mathematics could not rise to primus inter pares among the sciences by simply providing tools for the special sciences. It also had to strengthen its disciplinary autarky. Mathematics could only flourish in the postwar period if it stood apart from those applied disciplines whose political commitments produced continual scrutiny in the McCarthy period. If all mathematics were applied mathematics, and applications bore political weight in the cold war era, mathematicians would live under the same security regime as did nuclear physicists. This is the background of the renewed valorized distinction between "pure" and "applied" mathematics: the latter was potentially contaminated by the applications which existed outside mathematics, while the former entailed no commitment to any ideas which were not mathematical ideas. ${ }^{19}$ This relief from responsibility associated with mathematical purism is openly assumed by Jean Dieudonné, writing on behalf of Bourbaki:

${ }^{19}$ The therapeutic efficacy of mathematics was of course no novelty. The Cambridge mathematician G. H. Hardy, whose book Pure Mathematics was a major success after its initial publication in 1908, wrote about these matters in a poignant essay A Mathematician's Apology. Published in 1940 with the encouragement of C. P. Snow to help Hardy overcome his profound depression over the start of the Second World War, the essay allowed Hardy to say that, as a serious mathematician, "I have never done anything 'useful'. No discovery of 
Why do applications [of mathematics] ever succeed?

Why is a certain amount of logical reasoning occasionally helpful in practical life? Why have some of the most intricate theories in mathematics become an indispensable tool to the modern physicist, to the engineer, and to the manufacturer of atom-bombs? Fortunately for us, the mathematician does not feel called upon to answer such questions. (Bourbaki $1949,2)$

This Bourbakian aloofness was vital for its success in the United States. Bourbaki mathematics became metonymous for pure mathematics, particularly at Chicago.

The story of the reconstruction of the Chicago mathematics department begins with Marshall Stone. Having done classified research for the U.S. Navy and the Department of War until 1945 while on leave from Harvard, he was, on the advice of von Neumann, asked by Chicago's President Robert Hutchins to re-build Chicago's mathematics department in 1946 (after the war had left five senior positions vacant). Chicago had hosted the Manhattan project and in order to hold on to scientists such as Enrico Fermi, James Franck, and Harold Urey, the mathematics department needed strengthening (see Mac Lane 1989: 146). Stone was a magnificent administrator who knew that to pilot mathematics into new postwar waters he should take advantage of the opportunity to recruit first-rate émigré mathematicians, above all the single most important hire, André Weil - one of Bourbaki's leaders who managed to escape Europe in $1941 .^{20}$

In this period at Chicago, there was a ferment of ideas, stimulated by the newly assembled faculty and reflected in the development of the remarkable group of students who came to Chicago to study. Reports of this excitement came to other universities; often students came after hearing such reports. (Mac Lane 1989, 146-148)

As German mathematics had self-destructed with the purges of Jewish scholars, and with American mathematics still backward compared to European scholarship, Bourbaki represented a new and exciting integrative vision of the

mine has made, or is likely to make, directly or indirectly, for good or ill, the least difference to the amenity of the world." (Hardy [1940] 1969, 150)

${ }^{20}$ As full professor Stone hired Antoni Zygmund (originally from Poland), Shiing-Shen Chern (originally from China) and, as noted, Saunders MacLane from Harvard, all of whom arrived in 1947. As assistant professors he hired Irving Siegel, Edwin Spanier, and Paul Halmos (originally from Hungary) who was the former assistant of John von Neumann at the Institute for Advance Studies. Irving Kaplansky and Abraham A. Albert remained from the old faculty. 
discipline of mathematics, one which took hold internationally in the period from the end of the 1940s through the late 1960s (Corry 1992; Weintraub and Mirowski 1994). The Theory of Sets volume had appeared in 1939, but the war's dislocations meant that subsequent volumes only began appearing in 1947. Those new volumes took up topology, algebra, functions of one real variable, and integration. The younger Bourbaki group members who were either members of, or passed through, the departments in Chicago and Princeton were (besides André Weil) Samuel Eilenberg, Armand Borel, Serge Lang, Claude Chevalley, and John Tate. They in turn had close contacts with other members like Pierre Samuel, Jean-Pierre Serre, and Jean-Louis Koszul (see Weil 1991: 178).

The connections between the Chicago mathematics department and the Cowles group were manifest in the work of several mathematicians. Israel $\mathrm{N}$. Herstein, who was to write the important textbook Topics in Algebra, was connected to the Cowles group after his 1952 appointment as Assistant Professor at Chicago in Mathematics and Economics. In mathematics he worked closely with Albert, while he also wrote several Cowles Commission Discussion Papers on optimization concepts and efficiency. That same year Herstein would write a paper jointly with the Princeton and RAND mathematician (and future Field Medalist) John Milnor, which must have been a blueprint for the style the future "Neo-Walrasians" wished to develop (Herstein and Milnor 1953). ${ }^{21}$ We have already mentioned that Murray Gerstenhaber, a Ph.D student of Albert, wrote the exceptional paper on convex polyhedral cones for the Activity Analysis Conference and volume.

Morton L. Slater was another mathematician affiliated with Cowles as a "Research Consultant". He was to serve as the referee of most of the papers at the 1948 activity analysis conference. Slater was a University of Wisconsin graduate who did his graduate work in mathematics at Harvard. In that period he also had the title of Senior Mathematician, (Navy) Ordinance Research, Chicago, Illinois. In Cowles' Annual Report for the year 1950/51, Slater is described as a Research Associate who "provided mathematical advice and criticism with regard to the work of many staff members and provided expository presentations of mathematical results to economists." (Cowles Report 1951).

Not only did the mathematics department influence Cowles; the reverse was also true. Marshall Stone had certainly strengthened pure mathematics at Chicago but he was also concerned about the place of applied mathematics in his department. In seeking to broaden the Chicago mathematics community, Stone was to turn to the Cowles group for help.

During my correspondence of [19]45-46 with the Chicago administration I had insisted that applied mathematics should be a concern of the department, and I had outlined plans for expanding the

21 Herstein was, next to Andre Weil, one of the early mathematical confidents of Debreu. He also became Debreu's first co-author jointly writing a mathematical paper "Non-Negative Square Matrices" (Debreu and Herstein 1953). 
department by adding four positions of professors of applied subjects.... Circumstances were unfavorable.... On the other hand, there was pressure for the creation of the Department of Statistics, exerted particularly by the economists of the Cowles Foundation. A committee was appointed to make recommendations to the administration for the future of statistics with Professor Allen Wallis, Professor Tjalling Koopmans, and myself as members. Its report [urged] the creation of a Committee on Statistics, Mr. Hutchins being firmly opposed to the proliferation of departments. The committee enjoyed powers of appointment and eventually of recommendation for higher degrees.....and developed informal ties with the Department of Mathematics. (Stone 1989: 188-189)

Thus the presence of the Cowles Commission diminished pressure on the mathematics department to integrate applied mathematics into its curriculum. Put simply, Cowles and the Chicago mathematics department were in a mutually stabilizing relationship: Cowles allowed the mathematics department to maintain the disciplinary hierarchies and thus its disciplinary autarky while connection to the mathematics department rather than the economics department allowed Cowles to avoid the charge of political advocacy. Mathematical economics functioned as a buffer that allowed the "image conflict" within mathematics to become visible but not fraught. ${ }^{22}$ Given this shared dependence it is obvious that the ties of the Cowles Commission to the mathematics department were tighter than to the economics department, and helps to explain why few at Cowles were deeply involved in the controversies energizing the larger economics profession.

Unlike Chicago, Princeton's mathematics department hardly needed strengthening. Einstein, von Neumann, Gödel, and Weyl brought Göttingen and Vienna to the Institute for Advanced Study in the early 1930s, and with Oswald Veblen and James Alexander moving to the Institute from the university, it became the center of the mathematical universe. Veblen, who had been Princeton's department chair, helped leadership pass to Solomon Lefschetz who was soon to recruit a remarkable faculty by replacing senior retirees with

22 This sheds some light into the open question of the surviving "tacit hierarchies" (Dalmedico 1996) in mathematics between the pure and the applied despite of the increasing importance of the latter. A Field Medal for an applied mathematician, let alone for an economist, is still a wooden iron. A Nobel Prize in economics for a mathematician, who hesitantly accept it, is not uncommon. 
young stars like Alonzo Church, William Feller, A. W. Tucker, S. S. Wilks, and Emil Artin. ${ }^{23}$

In contrast to the unified mathematical spirit developed by Marshall Stone and André Weil at Chicago, the mathematical hothouse of Fine Hall, home to the Princeton University mathematics department, hosted an assemblage of subgroups in which a hierarchy emerged from topology at the top - represented by Salomon Lefschetz - to game theory at the bottom - represented by Albert William Tucker. ${ }^{24}$ Tucker, a former student of Lefschetz's, supervised virtually all the top game theory students (David Gale (PhD 1949), John Nash (PhD 1950), Lloyd Shapley (PhD 1954), and Marvin Minsky (PhD 1954)). Though supervised by Fox, Harold Kuhn belonged to this group too, as well did Leon Henkin. Gale, Kuhn, and Tucker ran a weekly seminar on game theory and its computational uses. ${ }^{25}$

While the Cowles Commission had some productive contact with the Chicago economics department especially in teaching statistics and mathematical economics, Tucker's group was entirely uninvolved with the Princeton economics department. Oskar Morgenstern was the lone representative of recent developments in economic theory though his students rather shunned economic theory. Shubik recalled:

The graduate students and faculty in the mathematics department interested in game theory were both blissfully unaware of the attitude in the economics department, and even if they had known of it, they would not have cared ... The contrast of attitudes between the economics department and

${ }^{23}$ Mac Lane $(1989,220)$ recalled the Princeton ditty about Lefschetz: "Here's to Lefschetz, Solomon L./Irrepressible as hell/When he's at last beneath the sod/He'll then begin to heckle God."

${ }^{24}$ Around Lefschetz, there was Ralph R. Fox and Norman Steenrod representing topology (just as in Chicago). Steenrod and the Bourbakian Samuel Eilenberg worked on homology theory. Fox's most important student was John Milnor who, even before concluding his PhD on link groups, had collaborated with Israel Herstein on an axiomatic approach to utility theory (1953). Separate from the Lefschetz students, there was Salomon Bochner working in analysis. Herbert Scarf, who would come to be known for the computational use of the fixed-point theorem in general equilibrium analysis, was supervised by Bochner. Then, there was a group around Alonzo Church in logic, and Emil Artin in algebra with his students John Tate and Serge Lang, who would both become leading Bourbakists.

25 Shubik also lists others connected to game theory at Princeton: Richard Bellman, Hugh Everett, John Isbell, Samuel Karlin, John Kemeny, John Mayberry, John McCarthy, Harlan Mills, William Mills, Norman Shapiro, Laurie Snell, Gerald Thompson, David Yarmish, Ralph Gomory, and William Lucas (Shubik 1992, 153). None of these individuals were connected to the community of economists. 
the mathematics department was stamped on my mind soon after arriving at Princeton. The former projected an atmosphere of dull business-as-usual conservatism of a middle league conventional Ph.D. factory; there were some stars but no sense of excitement or challenge. The latter was electric with ideas and the sheer joy of the hunt. Psychologically they dwelt on different planets. If a stray ten-year-old with bare feet, no tie, torn blue jeans, and an interesting theorem had walked into Fine Hall at tea time, someone would have listened. When von Neumann gave his seminar on his growth model, with a few exceptions, the serried ranks of Princeton Economics could scarce forbear to yawn. (Shubik 1992: 152-3)

None of the participants at the Activity Analysis conference, however, would yawn. Von Neumann's (1932 (1945)) earlier work in growth theory influenced nearly all conferees. That paper examined the possibility of existence of equilibrium of an economy whose various interconnected parts exhibited uniform rates of growth. It was the first paper related to economics which used a topological fixed point argument to achieve an equilibrium solution. The fact that general equilibrium analysis was reinvigorated at Cowles after 1949 was a direct result of the rediscovery of this paper and the important role it played by introducing topological methods.

\section{John von Neumann}

Von Neumann, hosted at the Institute for Advanced Study, was the shining mathematical star of war time engineering, operations research, and game theory. As André Weil, the Chicago representative of Bourbaki, personified the new intellectual purity in economic theory, at Princeton John von Neumann's authority fused pure mathematics with the eclectic spirit of applied research. ${ }^{26}$ Both as a mathematician and wartime consultant on numerous secret projects, von Neumann, "a socially and culturally different persona for the

${ }^{26}$ Recent historical work has placed von Neumann accurately in the intellectual and government communities of the early Cold War era. In an unusual historiographic confluence, the long period in which von Neumann was either ignored, castigated as a war-monger like Kubrick's Dr. Strangelove (Heims 1980), or treated as a genius to be worshipped (Macrae 1992) has been followed by serious historical studies of von Neumann's complex mathematical and personal history, and his profound importance not only to U.S. military efforts during WWII but to atomic energy, atomic weaponry, and computers in the postwar period (Asprey 1990; Dalmedico 2001; Mirowski 2002; Israel and Gasca 2009; Leonard 2010). 
mathematicians" (Dalmedico 1996: 149), was akin to the old-fashioned long distance operator of the 1930s: he coordinated all conversations.

There were two ironies in the resurrection of von Neumann's growth model. Von Neumann, just as his co-author and conference participant Oskar Morgenstern, was hostile to competitive economic analysis. The central theorem of the growth equilibrium paper was connected to his earlier 1928 proof of the minimax theorem for two person zero sum games. While there (von Neumann 1928) he had provided no reference to any economic tradition, the growth model paper referred to a "typical economic equation system" (ibid., 1). While the former modeled strategic behavior, the latter modeled competition. In his and Morgenstern's 1944 Theory of Games and Economic Behavior, strategic behavior and competitive behavior were expressly opposed to one other (1953 [1944], 15) while the two papers' central theorems were "oddly connected," being reducible one to one another via a saddle point (1945 [1936], 1). Von Neumann and Morgenstern wondered whether "there may be some deeper formal connections here (...). The subject should be clarified further." (1953 [1944], 154) Without anyone at the time ever clarifying this further, the equivalence made possible the steady crowding out of game theory as an alternative "paradigm" to competition. The different economic intuitions that had separately evolved in game theory and in perfect competition analysis merged since they were both amenable to the same topological methods. Von Neumann himself did no further work in competitive equilibrium analysis, or any economics, nor did he return to work on topological fixed point proofs.

There is a second irony to von Neumann's influence. By the late 1940s, von Neumann began pursuing algorithmics and the computational use of mathematics eschewing the Bourbakist approach to mathematics. His 1947 paper "The Mathematician" stated clearly his view that difficult problems in science generated the most important mathematical discoveries, and that a mathematics dependent only upon itself would soon become uninteresting, even to mathematicians. This view was entirely anti-Bourbaki. These ideas were represented at the conference by his colleague A. W. Tucker. Kuhn and Tucker developed von Neumann's minimax theorem for computational uses thus following von Neumann's anti-Bourbaki lead in mathematical engineering. It is for this reason that the developments in linear programming, game theory, and operations research began to merge. The notion of strategic behavior was lost to economics as it moved into the foreground of organizational questions. The Theory of Games and Economic Behavior was thus pushed away from the mainstream culture in economics. ${ }^{27}$ As Shubik witnessed,

${ }^{27}$ This was the period in which von Neumann gave a game theory talk to the economics department at MIT and on returning to Princeton told Morgenstern that "Samuelson is no mathematician ....and even in 30 years he won't absorb game theory" (quoted in Mirowski 2002, 139n41). It is in this light that one might reconsider Samuelson's role in the conference (representing the link to traditional economic theory) as a person providing a buffer rather than link (see Backhouse 2012). 
By 1947 von Neumann had conjectured the relationship between the linear programming problem and its dual and the solution of zero-sum two-person games. Gale, Kuhn, and Tucker started to investigate this more formally by 1948 and published their results in 1951. (...) The seminar at Fine Hall lumped the newly developing mathematics of game theory and programming together. Although there was a beautiful link between the mathematics for the solution of two-person zero-sum games, to a certain extent this link may have hindered rather than helped the spread of game theory understanding as a whole. For many years operations research texts had a perfunctory chapter on game theory observing the link to linear programming and treating linear programming and game theory as though they were one. The economics texts had nothing or next to nothing on the topic (1992: 159).

While Shubik contrasted von Neumann's game theory with programming, Dantzig, who had discovered linear programming, could equally credit von Neumann as his source. The link is revealed in Robert Dorfman's (1984) particularly lucid account of Dantzig's "Eureka moment" of discovering linear programming two years before the conference. Dorfman quoted an unpublished memoir from 1976 by George Dantzig as follows:

On October 1, 1947, I visited von Neumann for the first time at the School [sic] for Advanced Study at Princeton. I remember trying to describe to von Neumann the Air Force's problem [of airframe production]. I began with the formulation of the linear programming model in terms of activities and items, etc. Von Neumann did something which (I believe) was not characteristic of him. "Get to the point", he said impatiently. Having a somewhat low kindlingpoint myself at times, I said to myself, "OK. If he wants a quick version of the problem, then that's what he will get." In under one minute I slapped a geometric and the algebraic version of the problem on the board. Von Neumann stood up and said, "Oh that!" He then proceeded for the next hour and a half to lecture to me on the mathematical theory of linear programs (as it later came to be called). At one point seeing me sitting there with my eyes popping and my mouth open (after all I had searched the literature and found nothing), von Neumann said something like this: 'I don't want you to think I am 
generating this out of my head on the spur of the moment. I have just recently completed a book with Oskar Morgenstern on the theory of games. What I am doing is conjecturing that the two problems are equivalent. The theory that I am outlining to you is really an analog of the one that we have developed for the theory of games.' Thus I learned about Farkas's lemma and about duality for the first time (Dantzig 1976, p. 18 in Dorfman, privately printed at the University of Rochester, April 21, 1984, unpaginated)).

There followed a series of memoranda back and forth between von Neumann and Dantzig in one of which there is a footnote crediting Koopmans for "making suggestions on which the procedure for moving from one simplex to a better one is based." (Dorfman 1984, 292; see also Backhouse 2012: 6) Dantzig visited Cowles in June 1947, met Koopmans, and discovered the same interests. In June 1948, Dantzig visited Princeton to work with Kuhn, Gale on a solution of the duality problem, from which the Kuhn-Tucker theorem emerged. And so Koopmans, Dantzig, and Kuhn became the central figures in the conference for activity analysis in June 1949.

\section{The conference as origin}

With the preceding as multiple contexts for the 1949 conference, we are now able to interpret in what ways the conference was an "origin" of the changes that were to occur in economic theory. The conference produced the historical conditions for the integration of economic theory first by taking mathematical values of rigor and axiomatization for granted, and second by disengaging with the intellectual values that had shaped economics departments. Both the discipline of economics and the profession's postwar institutions were simply out of focus for the conferees. The conference appears to have been a gathering of scholars pulling at the same string instead of the public emergence of a sub-community with a shared purpose of converting the rest of the profession - not even the Econometric Society let alone the AEA - to their vision of the future of economic research. The conference could be an "originating event" only because the participants did little quarrel about the possible consequences of their work. In the no-man's-land between university and laboratory as well as between the traditional disciplines, the tensions that war time research created for both the mathematics and economics department could be ignored at the conference. Different institutional backgrounds, different theoretical threads, different epistemological justification for, and pragmatic relevance of, their work merged without being confronted one with another. The participants, instead, enjoyed living their skills while only implicitly agreeing on their meaning.

Certainly some participants might have believed that their work was going to represent new technical standards in the growing Econometric Society. But they would also have to know that, in 1949, at least half of the Econometric 
Society, and certainly most members of the American Economic Association, were in no position to appreciate their work. If the late 1940s graduate textbooks and syllabi taught no appreciation of Samuelson's modernization of Keynes and Hicks, how could the conferees believe they could convince economists of the power of the new techniques that went far beyond those of Samuelson and Hicks? Who of the participants would have been willing to proclaim the emergence of the new mathematical economics at an AEA roundtable on mathematics and economics that had been organized at the 1951 meetings with panelists Samuelson, Knight and Machlup! (AER 1952). What was topology to Knight or Machlup?

There certainly were some participants who were willing to confront others' views with their vision of social science and its responsibilities. We have already noted that Tjalling Koopmans acted as the spokesman of the conference, framing the possible interpretations and uses of activity analysis while contextualizing its underlying traditions. It was Koopmans who was willing to present his vision in front of a joint meeting of the Econometric Society and the American Economic Association half a year after the conference (Koopmans 1951). It was he who was active in linking the various emergent theories with the theoretical tradition of welfare economics. It was also Koopmans who in 1957 would write the only piece that defended the theoretical turn at Cowles in methodological terms, in his famous Three Essays on the State of Economic Science (1957).

In contrast there was only one conferee willing to challenge the emergent Cowles perspective, namely Oskar Morgenstern (discussing method, as he already did and was known for ever since the 1930s - see Boumans 2012). His three page paper warned readers of the lack of accuracy of the "observations" underlying the data used in linear programming. There is neither evidence for the belief, nor does the previous contextualization suggest, that other participants would react with strong emotions. ${ }^{28}$ One related point of disagreement might have been Leontief's input-output model and its apparent empirical applications. But given Leontief's absence, one might easily imagine that his model was not discussed as a challenge to theory, but as an interesting addition to method. ${ }^{29}$

${ }^{28}$ Backhouse argues the contrary: "It is ... impossible not to speculate that the conference had developed in a way that Leontief either did not like or about which he was ambivalent... When compared with the conference proposal and the list of papers discussed, the monograph focused on abstract theory at the expense of both statistical data and institutional arrangements" (2012: 32/38).

29 Morgenstern, who had never been a researcher at Cowles, some years later made a political issue out of his methodological inhibitions of emphasizing theory at the cost of thinking about data (see also Mirowski 2002: $394 \mathrm{ff})$. In 1953, in a letter to Rosson L. Cardwell, executive director of the Econometric Society, about the criteria for being named a Fellow of the Econometric Society, Morgenstern opined "[I]n my view the Fellow ought to be persons who have done some econometric work in the strictest sense. That is 
Since these challenges were hardly public, the activity analysis conference was little noted in the community of economists at the time. It was not seen at the time as a signal event. Unless economists were regular readers of Econometrica they would not even have been aware of these new ideas in mathematical theory, and even statistically interested readers of that journal would have had little connection to the conference's papers. In retrospect, the conference became a marker event because it was both exclusive and informal. The conferees had the freedom to not worry about the historical weight of their work, a liberty that had its source in the presentist problem-directed culture of mathematics departments.

The conference showcased the shared and interrogated methodological commitment free from any doxic baggage (Chandler 2009). This communal character characterizes a shift from economics writing as a literary production to economics as an exercise in scientific authorship. ${ }^{30}$ This shift was heralded in Koopmans' letter to the authors of the articles in the conference volume: "Since the subject of the volume has been furthered through conversations and conferences as much as through publications, it is suggested that authors feel free to refer to individuals as the source of ideas whenever there are no publications to which to refer" (July 8, 1949). Issues of scientific credit have a particular character in such an intellectual environment. If science in-the-making is a communal effort, a matter of conversation rather than contemplation, the intimate connection between authors and ideas becomes problematic (Düppe and Weintraub 2014). Koopmans' letter alluded to this problem.

Given his own history of taking matters of scholarship personally, it is hardly surprising that Nicholas Georgescu-Roegen was the first to raise issues of credit and priority with respect to the conference. He claimed that his results were "first presented at March 22, 1949 at a meeting of the staff of Harvard Economics Research Project." (Koopmans to Samuelson February 3, 1950). That is, Georgescu-Roegen claimed equal credit for Samuelson's theorem on the possibility of substitution in Leontief models. Samuelson replied (February 5, 1950): "I see no reason to question Georgescu-Roegen claim to independent discovery of the theorem concerning non-substitutability in the Leontief system. I only wonder that it was not discovered sooner by someone." This short exchange documents the confrontation of two scientific attitudes. In one there is reference to a world in which individuals have agency in conceiving truth. In the

today, they must have been in one way or another in actual contact with data they have explored and exploited" (in Louca and Terlica 2011: 75). Marschak entered that debate and argued that, in this case, one had to exclude members such as John von Neumann. Of course this showed how much the Econometric Society had learned to overlook the empirical verve of the later John von Neumann.

${ }^{30}$ Emmet (2011) describes the evolution of the unique workshop system in the economics department being decisive for the success of the "Chicago school". The Activity Analysis Conference can be seen as a very early manifestation of this culture that would later, specifically after Cowles's move to Yale, cross political boundaries in Chicago. 
other truth is the outcome of shared projects. In the former individuals claim credit, in the latter it is virtuous to give maximum credit to the larger community.

One cannot undervalue the Activities Analysis Conference. In Karen Knorr-Cetina's phrase, it announced the birth of a new epistemic community. The conference showcased a new intellectual culture in economics as a communal effort based on shared and un-interrogated standards of evidence, rigor, and techniques embracing different and even conflicting visions of the nature of economic science. The new economics was to be defined by skills and techniques rather than by ideas and canonical texts created by solitary geniuses and founders of "schools of thought". The conference performed this new culture in which establishing truth requires the cooperation of specialized intellects with a variety of skills. The conferees did not quarrel about their different backgrounds, their different intellectual socializations, or the diverse possible consequences of their work. Instead they collectively (modulo Georgescu-Roegen) enjoyed living their skills and sharing them, one with another. The conference thus pointed a way forward in which the sense of shared purpose that characterized a great deal of wartime science could carry over to peacetime economic analysis. 


\section{References}

Amadae, S. M. (2003). Rationalizing Capitalist Democracy: The Cold War Origins of Rational Choice Liberalism. Chicago, University of Chicago Press.

Arrow, K. J. (1951). "Mathematical Models in the Social Sciences". Policy Sciences in the United States. H. D. Lasswell and D. T. Lerner. Stanford, CA, Stanford University Press: 129-154.

Arrow, K. J. (1991). "Cowles in the History of Economic Thought". Cowles Fiftieth Anniversary: Four essays and an index of publications. C. Foundation. New Haven, The Cowles Foundation.

Arrow, K. J. (2008). "George Dantzig in the development of economic analysis". Discrete Optimization 5: 159-167.

Arrow, K.J. (2009). "Some Developments in Economic Theory since 1940: An Eyewitness Account." The Annual Review of Economics, 1:1-16.

Asprey, W. (1990). John von Neumann and the Origins of Modern Computing. Cambridge, MA, MIT Press.

Augier, M. and J. G. March (2011). The Roots, Rituals, and Rhetorics of Change: North American Business Schools after the Second World War. Stanford, CA, Stanford University Press.

Roger Backhouse and Philippe Fontaine (eds.) (2010). The History of the Social Sciences since 1945. New York: Cambridge University Press.

Boumans, M. (2012). Observations in a hostile environment: Morgenstern on the accuracy of economic observations. History of Observations in Economics. H. Maas and M. S. Morgan. Durham, NC, Duke University Press, 110-131.

Biagioli, M. and P. Galison (eds.) (2003). Scientific Authorship: Credit and Intellectual Property in Science. New York and London: Routledge.

Bockman, J. and M.A. Bernstein (2008). "Scientific Community in a Divided World: Economists, Planning, and Research Priority during the Cold War." Comparative Studies in Society and History, 50 (3): 581-613.

Burns, A.F. and W.C. Mitchell (1946). Measuring Business Cycles. NBER Book Series Studies in Business Cycles.

Bush, V. (1945). "Science, the endless frontier. A report to the President." Washington, D.C., (United States) Office of Scientific Research and Development.

Conant, J.B. 1947. On Understanding Science: An Historical Approach. Yale University Press.

Corry, Leo (1992). "Nicolas Bourbaki and the concept of mathematical structure," Synthese, 92: 315-348.

Cottle, Richard W. (2010). "A brief history of the International Symposia on Mathematical Programming." Mathematical Programming, Ser. B, 125: 207233.

Dalmedico, Amy D. (1996). "L'essor des mathématiques appliqueés aux États-Unis: L'impact de la seconde guerre mondiale." Revue d'histoire des mathématiques, 2: 149-213. 
Dalmedico, Amy D. (1997). Mathematics in the Twentieth Century. Science in the Twentieth Century. J. Krige and D. Pestre. Amsterdam, Harward Academic: 651-667.

Dalmedico, Amy. D. (2001). "An Image Conflict in Mathematics After 1945." In Changing Images in Mathematics: From the French Revolution to the New Millenium. U. Bottazzini and A. D. Dalmedico (eds.). London and New York, Routledge: 223-253.

Dantzig George B (1982). "Reminiscences about the Origins of Linear Programming". Operations Research Letter, 1 (2): 43-48.

Debreu, Gerard (1983). "Mathematical economics at Cowles." Cowles Fiftieth Anniversary. Klevorick. Cowles Foundation at Yale University.

Debreu, G. and I. N. Herstein (1953). "Nonnegative Square Matrices." Econometrica 21(4): 597-607.

Dickson, D. (1988). The New Politics of Science. Chicago, University of Chicago Press.

Dorfman, R. (1984). "The Discovery of Linear Programming." Annals of the History of Computing 6(3): 283-295.

Düppe, T. (2012). "Gerard Debreu's Secrecy: His Life in Order and Silence." History of Political Economy, 44 (3): 413-449.

Düppe, T., and E. Roy Weintraub (2014). Finding Equilibirum: Arrow, Debreu, McKenzie and the Problem of Scientific Credit. Princeton University Press.

Emmett, Ross B. (2011). "Sharpening Tools in the Workshop: The Workshop System and the Chicago School's Success". In van Horn, Robert, Philip Mirowski and Thomas Stapleford (eds.). Building Chicago Economics: New Perspective on the history of America's most powerful economics program, Cambridge University Press: 93-115.

Epstein, R. J. (1987). A History of Econometrics. Amsterdam and New York, North-Holland.

Erickson, P., J. L. Klein, et al. (2012). Chapter 2: The Bounded Rationality of Cold War Operations Research. The Strange Career of Rationality in the Cold War. Chicago, University of Chicago Press.

Feuer, L. S. (1982). "The Stages in the Social History of Jewish Professor in American Colleges and Universities." American Jewish History 71(4): 432-465.

Friedman, M. and L. J. Savage (1948). "Utility Analysis of Choices Involving Risk." Journal of Political Economy 56(4): 279-304.

Guglielmo, Mark (2008). "The Contribution of Economists to Military Intelligence During World War II." The Journal of Economic History, 68 (1): 109150.

Hardy, G. H. (1944 [1908]). A Course in Pure Mathematics. Cambridge, Cambridge University Press.

Hardy, G.H. (1969 [1940]). A Mathematician's Apology. Cambridge University Press.

Buck, P. S. et al. (1945). General Education in a Free Society. Cambridge, Mass.: Harvard Univ. Press.

Herstein, I. N. and J. Milnor "An Axiomatic Approach to Measurable Utility." Econometrica, 21 (2): 291-297. 
Heims, S. J. (1980). John Von Neumann and Norbert Wiener: from mathematics to the technologies of life and death. Cambridge, Mass., MIT Press.

Hicks, J. R. (1939). Value and Capital. Oxford, Oxford University Press.

Hollinger, D. A. (1996). Science, Jews, and Secular Culture: Studies in Mid-Twentieth Century American Intellectual History. Princeton, NJ, Princeton University Press.

Van Horn, Robert, Mirowski, Philip, and Thomas A. Stapleford (eds.) (2011). Building Chicago Economics: New Perspectives on the History of America's Most Powerful Economics Program. Cambridge University Press.

Israel, G. and A. M. Gasca (2009). The world as a mathematical game: John von Neumann and Twentieth Century Science. Basel: Birkhäuser.

Kakutani, S. (1941). "A Generalization of Brouwer's Fixed Point Theorem." Duke Mathematical Journal 8: 457-459.

Koopmans, Tjalling 1947. "Measurement without theory." Review of Economic Statistics 29: 161-72.

Koopmans, T. C., Ed. (1951). Activity Analysis of Production and Distribution: Proceeding of a Conference. Cowles Commission Monographs. New York, John Wiley and Sons.

Koopmans, T.C. (1951b). "Efficient Allocation of Resources." Econometrica 19 (4): 455-465.

Koopmans, T. C. (1957). Three Essays on the State of Economic Science. New York, McGraw-Hill.

Kuhn, HW (2008). "57 years of close encounters with George", Kuhn on Dantzig.pdf. from http://www2.informs.org/History/dantzig/articles_kuhn.html

Leggon, C. B. (2001). "The Scientist as Academic". The American Academic Profession. S. R. Graubard. New Brunswick, NJ, Transaction Publishers.

Leonard, R. L. (2010). Von Neumann, Morgenstern, and the Creation of Game Theory: From Chess to Social Science, 1900-1960. Cambridge and New York, Cambridge University Press.

Lipset, S. M. and J. Everett Carll Ladd (1971). "Jewish Academics in the United States: Their Achievements, Culture, and Politics." American Jewish Yearbook: 89-128.

Louçã, F. and Terlica, S. (2011). "The Fellowship of Econometrics: Selection and Diverging Views in the Province of Mathematical Economics, from the 1930s to the 1950s." History of Political Economy 43 supplement 1: 5785.

Lyman, S. M. (1994). "A Haven for Homeless Intellects: The New School and Its Exile Faculties." International Journal of Politics, Culture, and Society 7(3): 493-512.

MacLane, S. (1989). "Mathematics at the University of Chicago: A Century of Mathematics in America." Part II. P. L. Duran. Providence RI, American Mathematical Society: 127-154.

Macrae, N. (1992). John von Neumann. New York, Pantheon Books.

Merton, R. K. (1973). The Sociology of Science. Chicago, University of Chicago Press. 
Mirowski, P. E. (2002). Machine Dreams: Economics becomes a Cyborg Science. Cambridge University Press.

Mirowski, P. E. (2012). The Cowles Commission as an anti-Keynesian Stronghold. Microfoundations Reconsidered. P. G. Duarte and G. T. Lima. Cheltenham, UK and Northampton MA, Edward Elgar: 131-167.

Ortolano, Guy (2009). The Two Cultures Controversy: Science, Literature and Cultural Politics in Postwar Britain. Cambridge University Press.

Pias, C. (ed.) (2003/2004). Cybernetics - Kybernetic. The MacyConferences 1946 - 1953, Band 1: Transactions/Protokoll, Band 2: Documents/Dokumente. Zürich and Berlin: Diaphenes.

Samuelson, P.A. (1952). "Economic Theory and Mathematics: An Appraisal". The American Economic Review 42(2), Papers and Proceedings of the Sixty-fourth Annual Meeting of the American Economic Association: 56-66.

Samuelson, P. (1954). "Some Psychological Aspects of Mathematics and Economics." The Review of Economics and Statistics 36(4): 380-386.

Samuelson, P. MIT Interview http://mit150.mit.edu/infinite-history

Sapolsky, H. M. (1990). Science and the Navy: The History of the Office of Naval Research. Princeton, Princeton University Press.

Scarf, H.E. (1995). "Tjalling Charles Koopmans, 1910-1985: A Biographical Memoir" Washington: National Academies Press.

Scherer, F. M. (2000). "The Emigration of German-Speaking Economists after 1933." Journal of Economic Literature 38(3): 614-626.

Shubik, Martin (1992). "Game Theory at Princeton, 1949-1955: A Personal Reminiscence." History of Political Economy 24(Supplement): 151163.

Slater, Morton L. (1950). "Lagrange multipliers revisited," Cowles Commission Discussion Paper, Mathematics 403.

Stone, M. H. (1989). "Reminiscences of Mathematics at Chicago." $A$ Century of Mathematics in America. Part II. P. L. Duran. Providence RI, American Mathematical Society: 183-190.

von Neumann, J. (1928). "Zur Theorie der Gesellschaftsspiele". Mathematische Annalen 100: 295-320.

von Neumann, J. (1936). "Über ein ökonomisches Gleichungssystem und eine Verallgemeinerung des Browerschen Fixpunksatzes". Ergebnisse eines Mathematischen Kolloquiums 1935-36. K. Menger. Leipzig and Vienna, Franz Deuticke. 8: 73-83.

von Neumann, J. and O. Morgenstern (1944). The Theory of Games and Economic Behavior. Princeton, NJ, Princeton University Press.

von Neumann, J. (1945). "A Model of General Economic Equilibrium." The Review of Economic Studies 13(1): 1-9.

Wald, A. (1935). "Über die Produktionsgleichungen der ökonomischen Wertlehre (II)." Ergebnisse eines mathematischen Kolloquiums, 1934-35. K. Menger. Leipzig and Vienna, Franz Deuticke.

Birkhäuser.

Weil, A. (1991). The Apprenticeship of a Mathematician. Boston,

Weintraub, E. R. (1983). "The Existence of a Competitive Equilibrium: 1930-1954." Journal of Economic Literature 21(1): 1-39. 
Weintraub, E. R. (2002). How Economics Became a Mathematical Science. Durham, NC, Duke University Press.

Weintraub, E. R. and P. Mirowski (1994). "The Pure and the Applied: Bourbakism Comes to Mathematical Economics." Science in Context 7(2): 245272. 